\title{
Tolerogenic Dendritic Cells for Therapy of Immune-Mediated Inflammatory Diseases
}

\author{
Urban Švajger ${ }^{1,2}$ and Borut Štrukelj ${ }^{1}$ \\ ${ }^{1}$ University of Ljubljana, Faculty of Pharmacy, \\ ${ }^{2}$ Blood Transfusion Centre of Slovenia, Ljubljana, \\ Slovenia
}

\section{Introduction}

Within the complex array of numerous immunological processes that protect the host from invading pathogens and at the same time avoid excessive immune reactions with induction and maintenance of tolerance to self, the dendritic cells (DCs) have been designated as central players. Discovered and morphologically described by Steinman and Cohn almost 30 years ago, DCs have gained an ever-increasing interest from the scientific community (Steinman, Topliss et al. 1973). This has been even more pronounced throughout the last decade with the discovery that DCs not only serve as primary initiators of antigen (Ag)specific immune responses, but can also induce immunological tolerance and contribute to immune homeostasis maintenance by various mechanisms, including induction of regulatory T cells (Treg) (Steinman, Hawiger et al. 2003). Indeed, the DCs possess a unique set of biological tools that allows them to present Ag information to effector cells of the immune system in a way to promote tolerance induction by functional mechanisms such as T-cell anergy, deletion, apoptosis and instruction of different Treg types. Direct delivery of tolerogenic signals by DCs, most commonly to respective Ag-specific T cells, is in a great way determined by the DCs preliminary activation state, which itself is orchestrated by various environments that DCs find themselves in under both physiological and pathophysiological conditions. Today it is well-documented, that a number of immunosuppressive factors, either related to specific tissue microenvironments, microbial components or pharmacological immunosuppressants, can act on DCs in a way to cause their alternative activation or tolerogenic state (Weiner 2001; Hackstein and Thomson 2004; Rutella, Danese et al. 2006). In addition to immature (iDCs) which are known to act in an immunosuppressive fashion, the tolerogenic DCs (TDCs) can be said to do the same but in an even more efficient manner. Whereas tolerance induction by iDCs seems to rely mostly on insufficient delivery of co-stimulatory signals, TDCs express more elements of active tolerance induction, including surface inhibitory molecules and production of antiinflammatory cytokines, that are expressed depending on the nature of DC activation and/or development.

With DCs able to achieve greatly opposing states regarding their immunostimulatory status, together with the notion of manipulating DC function in the lab, scientists have put ongoing efforts into resolving the underlying mechanisms of DC-mediated tolerance induction. The 
development of quality protocols for in vitro/ex vivo generation of efficient TDCs still remains a hot topic. We are now witnessing the beginning of first clinical trials involving TDCs for the treatment of immune-mediated diseases and can expect a lot of development in this field in the near future. In this chapter, we will focus on up-to-date discoveries regarding the nature of TDCs and how this knowledge can be exploited for the benefit of successful future treatments of various immune-mediated disorders.

\section{Role of DCs in immunity and immune homeostasis}

In a sense of immunological function by definition, the role of DCs in general is that of a sentinel, which literally means that they are rather the carriers of antigenic information, rather than being effector cells per se. In the body, under physiological conditions, the DCs predominantly reside in tissues at body surfaces, where their main task is to actively sample the environment and process both endogenous and exogenous Ags, with the aim to be presented to Ag-specific T cells in secondary lymphoid tissues (Banchereau and Steinman 1998). As Ags are internalized and processed, they are targeted to MHC (major histocompatibility complex) class II-positive lysosomes. There, they are not immediately loaded into MHC II-peptide complexes, but are retained for later use as immunogenic peptides (Inaba, Turley et al. 2000). The activation state in which these DCs excel with their unique Ag-processing machinery is called an immature state. There are many specific characteristics that separate iDCs from their fully activated state that DCs encompass after full and optimal maturation process. Besides the ability of endocytosing Ag material, iDCs are characterized by low expression of co-stimulatory molecules, low or absent production of pro-inflammatory cytokines and low allo-stimulatory capacity, the latter also being associated with relatively low expression of MHC class I and II molecules on DC surface. It is thus said that iDCs, when in contact with the responding $\mathrm{T}$ cells, can induce tolerogenic outcomes via elements of passive tolerance (Lutz and Schuler 2002). In other words, the lack of co-stimulatory signals derived from iDCs, particularly signal 2 (co-stimulatory molecules) and signal 3 (pro-inflammatory cytokines), results in failure to initiate effector immune responses, but induce anergy and also Tregs instead.

In contrast, when iDCs are activated by various ligands that bind pattern recognition receptors or PRRs (e.g. LPS for toll-like receptor (TLR)4, viral RNA for TLR3, muramyl dipeptide (MDP) for nucleotide oligomerization domain (NOD) receptors, etc.) they change drastically in both their appearance and function (Banchereau and Steinman 1998; Mellman and Steinman 2001). This so called mature DC state, has for a long time, together with immature state on the other side, defined what has been understood by immunologists as two existing and opposing states of DC activation (Cella, Sallusto et al. 1997). Indeed, after maturation the function of DCs changes greatly towards the presentation of Ags processed under physiological conditions with the main task to induce effector $\mathrm{T}$ cell responses of different types including Th1, Th2 and Th17 (Lanzavecchia and Sallusto 2001; Moser 2003; Kadowaki 2007). This ability is associated with a number of morphological and phenotypical changes. In this manner, upon PRR activation by respective ligands, maturing DCs seize their Ag-sampling function and begin to express peptide-MHC complexes on their surface. In addition, down-regulation of tissue-homing chemokine receptors such as CCR1, CCR2 and CCR5 is initiated and they begin to express CCR7 which guides maturing DCs to lymph nodes. Mature DCs generally express high levels of MHC molecules and 
CD80, CD86, other co-stimulatory molecules, however they influence the $\mathrm{T}$ cell differentiation towards various effector types in a great way by the so called third signal, which represents the cytokine-producing profile of DCs. The latter is in great way dependant on the manner in which the DCs were activated, in other words, what type of danger signal induced their maturation. In response to certain bacteria, viruses and parasites, the DCs are instructed to produce large quantities of IL-12, as well as type I interferons (IFNs) (Banchereau and Steinman 1998; Pulendran, Palucka et al. 2001). Such DCs have the capacity to orchestrate Th1-type effector $\mathrm{T}$ cells, which later assist in the activation of macrophages and cytotoxic $\mathrm{CD}^{+} \mathrm{T}$ cells to kill respective pathogens that were encountered. Extracellular pathogens, for example helminthes, activate DCs in a way that they produce lower quantities of IL-12, but on the other hand increased amounts of IL-10 and IL-4, which can then shift the balance towards Th2 effectors (MacDonald and Maizels 2008). Other factors besides signal 3-mediators have been found recently to contribute to Th2 development. Indeed, the co-stimulator OX40L expressed by DCs has been recently found important (Blazquez and Berin 2008). It also must be noted, that induction of a Th2 profile is also significantly regulated by environmental instruction such as specific tissue derived factors and lipid mediators including prostaglandin D and E (MacDonald and Maizels 2008). Next, stimulation of DCs through the NOD2 receptor instructs DCs to produce IL-1, IL-6 and IL-23, which then induce IL-17 production and the differentiation of Th17 effector T cells (van Beelen, Zelinkova et al. 2007).

Besides effective Ag-sampling, the ability to induce immunosuppressive outcomes is another vital attribute of iDCs, that has been recently appointed with potential importance in the induction and maintenance of so-called peripheral tolerance. When we question the immunogenicity of a specific $\mathrm{Ag}$, be it e.g. a protein or a peptide, we soon encounter a complex issue consisting of many factors that are implicated in the way in which such Ag is presented to cells of the immune system. Indeed, many of these factors are directly associated or governed by DCs as professional antigen-presenting cells (APCs), as they can directly shape the way in which a naïve T cell "sees" the Ag itself. While strong Th1- or Th2type immune responses can only be induced by mature DCs (mDCs), iDCs can present the same Ag to induce tolerance, and in the peripheral immune networks, the latter seems to be of great importance. Just recently, there were theoretical challenges to such beliefs, since iDCs are known to reside mainly in tissues and do not express proper homing receptors, such as the chemokine receptor CCR7 and the ability to respond to lymph node homing ligands CCL19 and CCL21, that would guide these cells to secondary lymph nodes to allow sufficient DC-T cell contact. In addition, insufficient Ag-presentation on the surface of iDCs would hamper the recognition of Ag by T cells (Inaba, Turley et al. 2000). However, there is now proof that iDCs can migrate via afferent lymph and that they contribute significantly to peripheral tolerance to self, by up-take of apoptotic material from normal cell turnover. Antigenic material from apoptotic cells is then presented to naïve $\mathrm{T}$ cells by such iDCs which leads to tolerance induction due to lack of co-stimulation (Steinman, Turley et al. 2000). Thus iDCs constantly traffic from tissues to secondary lymph nodes carrying self-Ags to which they can cause anergic or regulatory responses upon encounter with naïve $\mathrm{T}$ cells. These findings and the importance of iDCs in peripheral tolerance were supported by several discoveries, demonstrating the tolerogenic ability of iDCs both in vitro and in vivo. It has been shown that when DCs in their immature state are injected into the recipient, they can inhibit established effector $\mathrm{T}$ cell responses and contribute to generation of Tregs (Dhodapkar, Steinman et al. 2001). In addition, iDCs are well-known to induce IL-10- 
secreting Tr1-type Tregs in vitro after repetitive stimulation (Jonuleit, Schmitt et al. 2000). Recently, Ohnmacht et al. performed an ingenious experiment, where they depleted most crucial DC types (conventional DCs, plasmacytoid DCs and Langerhans DCs) from the mice using diphtheria toxin A (DTA) cross-breeding with CD11c-Cre mice. Such DC ablation resulted in development of spontaneous autoimmunity and high incline in the number of effector Th1 and Th17 cells (Ohnmacht, Pullner et al. 2009).

\section{Tolerogenic dendritic cells (TDCs)}

The long lasting perception of DC maturity and immaturity as two extremes of DC immunomodulatory function was enriched through recent years with several discoveries. These highlighted even further the unique functional plasticity of DCs as APCs, presenting facts that DCs can achieve alternative activation states under specific circumstances that grant them superior immunosuppressive properties. In this manner, TDCs possess several characteristics which separate them from iDCs. First and foremost, TDCs are equipped with active mechanisms to induce immune tolerance which we will outline below and can therefore achieve stronger immunosuppressive effects in shorter time periods.

\subsection{Immunosuppressive mechanisms of TDCs}

The stimulation of T cells by DCs is a finely orchestrated process involving the interplay of many factors starting with TCR engagement, interaction of various co-stimulatory molecules and the effect of soluble effector molecules produced by DCs, as well as T cells and surrounding tissues. Whenever the T cells are stimulated via TCR (signal 1) with absent or insufficient further stimuli, their activation results in T-cell unresponsiveness or even apoptosis (Steinman, Hawiger et al. 2003). Induction of tolerance by iDCs, due to their immature state, can therefore be viewed upon as passive induction of tolerogenic immune response due to lack of additional necessary stimuli required for optimal T cell activation.

\subsubsection{IDO competence}

In case of TDCs, the increased activity of enzyme indoleamine-2,3-dioxygenase (IDO) is one of major mechanisms contributing to TDC immunosuppressive function. IDO catabolizes tryptophan, thereby causing its depletion and the formation of bioactive kynurenine byproducts. Both local depletion of tryptophan, as well as formation of kynurenines have been shown to affect $\mathrm{T}$ cell proliferation and survival, since tryptophan itself represents an essential amino acid required for their growth (Grohmann, Fallarino et al. 2003). IDO is encoded by the IDO1 gene and its expression can be found at low levels in several tissues (i.e., gut, brain, thymus, etc.), however high expression of IDO is strictly regulated and can be found particularly in APCs, such as DCs, in response to IFN- $\gamma$, but can be induced by type I IFNs as well (IFN- $\alpha$ and IFN- $\beta$ ) (Mellor and Munn 2004). Many studies have shown that IDO importantly regulates adaptive immune responses of T cells, thereby contributing to immune homeostasis. In animal models, the administration of 1-methyl-tryptophan, a small-molecule IDO inhibitor, into pregnant mice resulted in immediate rejection of an allogeneic fetus, confirming its role in maternal immune tolerance towards paternal alloantigens (Munn, Zhou et al. 1998; Mellor and Munn 2004). In this manner, it has been shown that IDO not only contributes to maternal tolerance but can control allograft rejection (Grohmann, Orabona et al. 2002; Cook, Bickerstaff et al. 2008) and ameliorate autoimmune 
diseases as well (Grohmann, Fallarino et al. 2003; Platten, Ho et al. 2005). In addition, IDOmediated immunosuppression has been demonstrated to play a role in decreased immunosurveillance of tumor tissues and its inhibition by pharmacological agents such as 1-L-methyl-tryptophan (1-MT) results in improved anti-tumor responses (Hou, Muller et al. 2007). In the center of all such and similar scenarios, the DCs themselves seem to be the main discriminatory factor in IDO-mediated tolerance induction, which is in many cases associated with either paracrine or autocrine signaling by IFN- $\gamma$ (Grohmann, Bianchi et al. 2000; Grohmann, Fallarino et al. 2003). In DCs, IDO can also be induced by the crosstalk between DCs and T cells. In this scenario, when the CD80 and CD86 molecules are engaged by inhibitory ligand CTLA-4 expressed on Tregs and also activated T cells, IDO is induced in a IFN- $\gamma$ fashion (Grohmann, Orabona et al. 2002; Fallarino, Grohmann et al. 2003), which strengthens the tolerogenic circuit and represents one of potential mechanisms through which DC tolerance is induced by interacting with Tregs.

Increased IDO-competence in TDCs therefore produces its immunosuppressive effects in two major ways: either by tryptophan starvation (which can affect the responding $\mathrm{T}$ cells directly as well as mediate by-stander suppression due to local depletion (Grohmann, Fallarino et al. 2003) or by the effects of bioactive tryptophan metabolites. Tryptophan degradation by IDO results in formation of kynurenine (Kyn), which can be further catabolized to 3-hydroxykynurenine (3-HK), 3-hydroxyanthranilic acid (3-HAA) and quinolinic acid (Quin). These kynurenines were shown to possess a plethora of effects on various immune cells. For example, Kyn, 3-HK and 3-HAA can suppress the proliferation of T cells and Kyn also affects the proliferation of NK cells (Orabona and Grohmann 2011). Furthermore, kynurenines can cause apoptosis themselves, as 3-HAA induces the apoptosis of $\mathrm{T}$ cells in a pyruvate dehydrogenase kinase (PDK)-1- and Nf-kB-dependent pathway (Hayashi, Mo et al. 2007). Also in several animal models, kynurenines and synthetic drugs similar to tryptophan catabolites, have ameliorated the severity of several immunemediated diseases including experimental autoimmune encephalomyelitis (EAE)(Platten, Ho et al. 2005), experimental asthma (Hayashi, Mo et al. 2007) and chronic granulomatous disease (Romani, Fallarino et al. 2008).

\subsubsection{Production of immunosuppressive cytokines}

In addition to low or absent production of IL-12p70, a cytokine directly involved in shaping of Th1-type immune responses (Vieira, de Jong et al. 2000), and in contrast to iDCs which are known to express low levels of both pro- and anti-inflammatory cytokines, the TDCs generated by various protocols produce high levels of anti-inflammatory cytokines, which play a major role in their superior tolerogenic capacity. Two major immunosuppressive cytokines produced by TDCs are IL-10 and TGF- $\beta$. Dendritic cells isolated directly from specific anatomic compartments such as the Peyer patches, lungs, or the anterior chamber of the eye, produce increased quantities of IL-10 and drive the differentiation of IL-10-secreting Tregs or Tr1 cells (Lutz and Schuler 2002). Interleukin-10 was first identified as a cytokine synthesis inhibitory factor or CSIF, since it has been realized that it acts as a potent inhibitor of cytokine production by Th1 cells (Moore, Vieira et al. 1990). Today it is well known, that IL-10 is one of most general immunosuppressive biomolecules in our immune system with the ability to affect many immune cell types (Moore, de Waal Malefyt et al. 2001). Interleukin-10 down-regulates the expression of co-stimulatory and adhesion molecules, as well as the expression of MHC class II molecules and inflammatory cytokines (Fiorentino, 
Zlotnik et al. 1991; Willems, Marchant et al. 1994). It modulates the stimulatory capacity of APCs and can induce anergy in both $\mathrm{CD}^{+}$and CD8 ${ }^{+} \mathrm{T}$ cells (Groux, O'Garra et al. 1997; Steinbrink, Wolfl et al. 1997; Allavena, Piemonti et al. 1998; Steinbrink, Graulich et al. 2002). In particular, the ability of TDCs to secrete large amounts of IL-10 has been directly associated with increased ability to induce Tr1 cells on many occasions. As stated above, iDCs have the potential to induce type 1 Tregs in vitro after repetitive stimulation(Jonuleit, Schmitt et al. 2000) and IL-10 is required for this process (Levings, Gregori et al. 2005). However, TDCs generated to produce high levels of IL-10 have been shown to do so more efficiently and in shorter time periods, inducing anergic T-cell lines after only one round of stimulation(Roncarolo, Gregori et al. 2006). Very recently, a new subset of IL-10-producing TDCs, termed DC-10, has been identified both in vivo and also induced in vitro (Gregori, Tomasoni et al. 2010). These DC-10 TDCs express high levels of inhibitory molecules, produce large amounts of IL-10 and have been shown especially efficient inducers of Tr1 cells in an IL-10-dependent manner.

Like IL-10, TGF- $\beta$ can suppress such functions as IL-12 production and co-stimulatory molecule expression by APCs, such as macrophages and DCs (Takeuchi, Alard et al. 1998; Geissmann, Revy et al. 1999) and thereby inhibits Th1 type immune responses. It is also a crucial cytokine involved in immunosuppressive mechanisms of $\mathrm{CD} 4{ }^{+} \mathrm{CD} 25^{+} \mathrm{FoxP} 3{ }^{+}$Tregs and plays a role in their induction and proper function (Andersson, Tran et al. 2008; Sakaguchi, Yamaguchi et al. 2008). Today, a number of experimental data strongly support the correlation between induction of tolerance via TGF- $\beta$, particularly in context of natural and peripherally induced FoxP3 ${ }^{+}$Tregs, and APCs, mainly the DCs(Belkaid and Oldenhove 2008). In both humans and mice, DCs can induce FoxP3 ${ }^{+}$Tregs from naïve CD4+ $\mathrm{T}$ cells in the presence of TGF- $\beta$. For example, in mice and rats, tumor cells have been shown to convert DCs into TGF- $\beta$-secreting TDCs that later induce the proliferation of Tregs (Ghiringhelli, Puig et al. 2005). Subsets of Treg-inducing DCs can also be found and isolated under physiological conditions. In the intestine, mesenteric lymph node CD103+ DCs have been characterized with potential to readily induce FoxP3 ${ }^{+}$Tregs in a TGF- $\beta$ - and retionic acid (RA)-dependent manner (Coombes, Siddiqui et al. 2007). In addition, $\mathrm{CD}^{+} \mathrm{CD}^{205^{+} \mathrm{DCs}}$ isolated from the spleen, preferentially produce TGF- $\beta$ and their induction of FoxP3 ${ }^{+}$Tregs can be prevented by blocking anti-TGF- $\beta$ (Yamazaki, Dudziak et al. 2008).

\subsubsection{Inhibitory molecules}

Another feature which adds to increased tolerogenic potential of TDCs is the surface expression of various inhibitory molecules which, in contrast to co-stimulatory molecules, deliver a negative signal to responding $\mathrm{T}$ cells and suppress their activation. Inhibitory molecules or sometimes referred to as co-inhibitory molecules, together with other signals derived from APCs, modulate and fine-tune the basic signaling through the TCR (signal 1). The discovery of inhibitory molecules and their understanding is just beginning to be understood and novel inhibitory candidates and their roles in DC-T cell communication are still being discovered.

Within the B7 family of proteins, programmed death ligand (PD-L)1 and PD-L2 are expressed on DCs throughout different activation states and can also be induced on other APCs, such as monocytes (Schreiner, Mitsdoerffer et al. 2004; Meier, Bagchi et al. 2008). Both PD-L1 and PD-L2 bind to their mutual receptor, the programmed death-1 (PD-1) (Freeman, Long et al. 2000; Latchman, Wood et al. 2001). Engagement of PD-1 by PD-L1-Ig and PD-L2- 
Ig fusion proteins has an inhibitory effect on $\mathrm{T}$ cell proliferation and cytokine production upon TCR stimulation. The presence of PD-L1 and PD-L2 on human monocyte-derived DCs is important for the attenuation of $\mathrm{T}$ cell activation, since blockade of both inhibitory molecules results in increased $\mathrm{T}$ cell activation and cytokine production (Brown, Dorfman et al. 2003).

Members of the immunoglobulin-like transcripts (ILT) family of proteins have been recently highlighted as important players in mechanisms of immune tolerance induction by DCs. Among these, the inhibitory receptors ILT3 and ILT4 have received most attention and have been recognized as an important descriptor of TDCs (Chang, Ciubotariu et al. 2002). Interaction of DCs with $\mathrm{CD}^{+}$suppressor cells (Ts) results in tolerization of the corresponding DCs with extensive up-regulation of ILT3 and ILT4 (Manavalan, Rossi et al. 2003). Both ILT3 and ILT4 can be induced by immunosuppressive factors including IL-10 and some pharmacological immunomodulators(Vlad, Piazza et al. 2003; Penna, Roncari et al. 2005; Svajger, Vidmar et al. 2008; Svajger, Obermajer et al. 2010). Manavalan et al. demonstrated that TDCs induced by IL-10 require ILT3 and ILT4 to induce tolerance in $\mathrm{CD}^{+} \mathrm{T}$ cells. Furthermore, newly discovered in vivo occurring TDC subset termed DC-10 requires the ligation of ILT4 to its receptor HLA-G for effective induction of Tr1 regulatory cells (Gregori, Tomasoni et al. 2010).

Another molecule important for peripheral immune homeostasis is a type II integral membrane protein belonging to the TNF superfamily called Fas ligand (FasL or CD95L) (Nagata and Golstein 1995). FasL is expressed on DCs and by interacting with its receptor Fas, it initiates a signaling cascade that leads to apoptotic cell death of cells bearing Fas. Apoptosis induced by Fas seems to play a pivotal role in T-cell homeostasis and control of cytotoxic $\mathrm{T}$ cell responses. In example, lymph node resident DCs in mice were shown to express functional FasL and serve as crucial regulators of $\mathrm{CD} 8^{+} \mathrm{T}$ cell responses during viral infection (Legge and Braciale 2005).

\subsection{Methods of TDC generation}

The term "alternative activation" has been used to describe the tolerogenic DC state and the name itself emphasizes the importance of DC activation state for its immunological function. The definition of "alternative activation" has mostly evolved through a number of in vitro/ex vivo based studies, exposing DC cultures to various biomolecules or pharmacological drugs with immunomodulatory potential, which in some cases resulted in a DC tolerization effect. Today, many protocols exist through which TDCs can be generated in the laboratory using different methods such as exposure to immunosuppressive cytokines or growth factors, immunosuppressive drugs or even by genetic modification of DCs to express immunosuppressive proteins.

Use of immunsuppressive cytokines such as IL-10 in DC cultures was one of the first approaches to generate TDCs and it demonstrated the option of effectively manipulating DC function towards tolerance induction (De Smedt, Van Mechelen et al. 1997; Steinbrink, Wolfl et al. 1997). Interleukin-10-treated iDCs had a significantly reduced allo-stimulatory capacity and were resistant to maturation, as was shown by a down-regulation of costimulatory molecules and an inability to induce effector T cell responses (Steinbrink, Wolfl et al. 1997). Furthermore, genetic engineering of DCs to express bioactive IL-10, using retroviral delivery system, results in DCs exhibiting extensive tolerogenic properties with significantly reduced capacity to induce allogeneic $\mathrm{T}$ cell proliferation and to generate cytotoxic T lymphocytes (CTLs) (Takayama, Nishioka et al. 1998). An important feature of 
tolerogenic DCs induced by IL-10, besides anergy induction of responding CD4 ${ }^{+} \mathrm{T}$ cells, is their ability to generate regulatory $\mathrm{T}$ cells, which are then able to suppress activation and function of other T cells in an Ag-specific manner (Steinbrink, Graulich et al. 2002).

The tolerogenic state of DCs can also be achieved with several other cytokines and biomolecules with potential immunosuppressive or pleiotropic properties such as transforming growth factor (TGF)- $\beta$ (Faunce, Terajewicz et al. 2004; Luo, Tarbell et al. 2007),

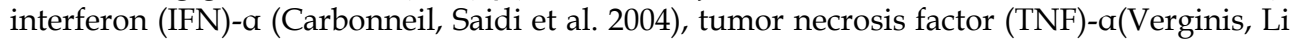
et al. 2005), vasoactive intestinal peptide (VIP) (Chorny, Gonzalez-Rey et al. 2005), IL-16 in combination with thrombopoietin (Della Bella, Nicola et al. 2004) and IFN- $\lambda$ (Mennechet and Uze 2006). All of the above mentioned factors can influence DCs in an immunosuppressive fashion, either guiding their differentiation from blood precursors towards a tolerogenic cell type, or influencing the activation or maturation of already differentiated DCs.

Many immunosuppressive drugs are known that induce DC tolerance by various mechanisms, frequently interfering with Nf-kB activation or acting on multiple levels of Nf$\mathrm{\kappa B}$ signaling pathway, as well as on other kinases such as p38 MAPK, IKB and others. For a critical reading on pharmacological TDC induction the reader is suggested to read focused review articles dedicated to the subject (Hackstein and Thomson 2004; Svajger, Obermajer et al. 2010). A classic example of DC maturation-inhibiting drugs are glucocorticoids (GCs) (Piemonti, Monti et al. 1999) and the activated form of vitamin D, 1,25-dihydroxyvitamin $\mathrm{D}_{3}$ $\left(1,25(\mathrm{OH})_{2} \mathrm{D}_{3}\right)$ (Piemonti, Monti et al. 2000). Glucocorticoids can inhibit the activity of Nf-kB via enhanced transcription and synthesis of IKBa(Auphan, DiDonato et al. 1995; Scheinman, Cogswell et al. 1995), which binds to Nf-kB in the cytoplasm and prevents its translocation to the nucleus or by direct association with the p65 Nf-kB subunit (Scheinman, Gualberto et al. 1995). These effects are based on GCs binding to their respective nuclear receptor, the glucocorticoid receptor (GR)(Scheinman, Gualberto et al. 1995; De Bosscher, Vanden Berghe et al. 2000).

Dendritic cells treated with dexamethasone (Dex) at $\mathrm{nM}$ concentrations prove resistant to maturation induced by TLR4 agonists, CD40L or TNF-a(Piemonti, Monti et al. 1999; Xia, Peng et al. 2005). Similar effects can be observed with $1,25(\mathrm{OH})_{2} \mathrm{D}_{3}$ (Berer, Stockl et al. 2000; Penna and Adorini 2000). Activation of DCs treated with either corticosteroids or 1,25 $(\mathrm{OH})_{2} \mathrm{D}_{3}$ leads to lowered expression of CD80, CD83, CD86 and both MHC class I and II molecules and display low allostimulatory capacity of responding T cells. After activation, such DCs show decreased production of IL-12, but produce great amounts of IL-10. The increased expression of IL-10 of activated TDCs most likely plays an important role in ensuring stable and maturation-resistant characteristics of treated DCs. Neutralization of IL10 using blocking mAbs during LPS-induced maturation of Dex-treated DCs allowed for partial maturation characterized by co-stimulatory molecule up-regulation (Xia, Peng et al. 2005). Increased IL-10 expression of DCs treated with corticosteroids seems to be associated with increased ERK signaling. It has been demonstrated that Dex-treated DCs activated with LPS show significantly higher phosphorylation levels of ERK (Xia, Peng et al. 2005). It is also known that induction of glucocorticoid-induced leucine zipper (GILZ) induced by GCs interferes with Nf-KB and MAPK/AP-1 signaling, preventing LPS-induced maturation of DCs, while at the same time up-regulates IL-10 production and expression of inhibitory molecule PDL-1 (Cohen, Mouly et al. 2006). Immunosuppression by $1,25(\mathrm{OH})_{2} \mathrm{D}_{3}$ is mediated by its nuclear receptor, the vitamin D receptor (VDR). Activation of VDR prevents $\mathrm{DC}$ maturation by inhibiting activity of Nf-KB by direct suppression of relB promoter by VDR (Dong, Lutz et al. 2005), as well as by inhibiting Nf-kB translocation, possibly by increasing stability of IкBa (Szeto, Sun et al. 2007). 


\begin{tabular}{|c|c|c|c|}
\hline Mediator & $\begin{array}{c}\text { Type of } \\
\text { immunomodulation }\end{array}$ & $\begin{array}{l}\text { Mechanisms of } \\
\text { suppression }\end{array}$ & References \\
\hline \multicolumn{4}{|c|}{$\begin{array}{l}\text { Cytokines/Growth } \\
\text { factors }\end{array}$} \\
\hline IL-10 & $\begin{array}{l}\text { Skewed maturation/ } \\
\text { Differentiation, TDC } \\
\text { induction }\end{array}$ & $\begin{array}{l}\text { T cell anergy, Treg } \\
\text { cells }\end{array}$ & $\begin{array}{l}\text { (De Smedt, Van Mechelen et } \\
\text { al. 1997; Steinbrink, Wolfl et } \\
\text { al. 1997; Steinbrink, Graulich } \\
\text { et al. 2002) }\end{array}$ \\
\hline TGF- $\beta$ & TDC induction & $\begin{array}{l}\mathrm{CD}^{+}{ }^{+} \mathrm{CD} 25^{+} \mathrm{FoxP}^{+} \\
\text {Treg cells }\end{array}$ & $\begin{array}{l}\text { (Faunce, Terajewicz et al. } \\
\text { 2004; Luo, Tarbell et al. 2007) }\end{array}$ \\
\hline IFN-a & $\begin{array}{l}\text { Skewed } \\
\text { differentiation }\end{array}$ & $\begin{array}{l}\text { IL-10 production, } \\
\text { naive CD } 4^{+} \mathrm{T} \text { cell } \\
\text { apoptosis, } \mathrm{Tr} 1 \\
\text { cells }\end{array}$ & (Carbonneil, Saidi et al. 2004) \\
\hline TNF- $\alpha$ & Semi-maturation & $\begin{array}{l}\mathrm{CD} 4+\mathrm{CD} 25^{+} \mathrm{FoxP} 3+ \\
\text { Treg cells }\end{array}$ & (Verginis, Li et al. 2005) \\
\hline VIP & $\begin{array}{l}\text { Skewed } \\
\text { differentiation, TDC } \\
\text { induction }\end{array}$ & Tr1 cells & $\begin{array}{l}\text { (Chorny, Gonzalez-Rey et al. } \\
\text { 2005) }\end{array}$ \\
\hline $\begin{array}{l}\text { IL-16 + } \\
\text { thrombopoietin }\end{array}$ & $\begin{array}{l}\text { Skewed } \\
\text { differentiation, TDC } \\
\text { induction }\end{array}$ & T cell anergy & $\begin{array}{l}\text { (Della Bella, Nicola et al. } \\
\text { 2004) }\end{array}$ \\
\hline IFN- $\lambda$ & $\begin{array}{l}\text { Skewed } \\
\text { differentiation, TDC } \\
\text { induction }\end{array}$ & $\begin{array}{l}\mathrm{CD} 4{ }^{+} \mathrm{CD} 25^{+} \mathrm{FoxP}^{+} \\
\text {Treg cells }\end{array}$ & (Mennechet and Uze 2006) \\
\hline $\begin{array}{l}\text { Pharmacological } \\
\text { agents }\end{array}$ & & & $\begin{array}{l}\text { (Svajger, Obermajer et al. } \\
\text { 2010) }\end{array}$ \\
\hline Glucocorticoids & $\begin{array}{l}\text { Inhibition of } \\
\text { maturation/ } \\
\text { differentiation }\end{array}$ & $\begin{array}{l}\text { T cell anergy, Treg } \\
\text { cells }\end{array}$ & $\begin{array}{l}\text { (Piemonti, Monti et al. 1999; } \\
\text { Xia, Peng et al. 2005) }\end{array}$ \\
\hline $1,25(\mathrm{OH})_{2} \mathrm{D}_{3}$ & $\begin{array}{l}\text { Inhibition of } \\
\text { maturation/ } \\
\text { differentiation }\end{array}$ & $\begin{array}{l}\text { T cell anergy, Treg } \\
\text { cells }\end{array}$ & (Piemonti, Monti et al. 2000) \\
\hline LF15-0195 & $\begin{array}{l}\text { Inhibition of } \\
\text { maturation }\end{array}$ & $\mathrm{T}$ cell anergy & (Yang, Bernier et al. 2003) \\
\hline Resveratrol & $\begin{array}{l}\text { Skewed } \\
\text { differentiation, TDC } \\
\text { induction }\end{array}$ & Tr1 cells & $\begin{array}{l}\text { (Svajger, Obermajer et al., } \\
\text { 2010) }\end{array}$ \\
\hline Niflumic acid & $\begin{array}{l}\text { Inhibition of } \\
\text { maturation }\end{array}$ & $\begin{array}{l}\text { low } \\
\text { allostimulatory } \\
\text { capacity }\end{array}$ & (Svajger, Vidmar, et al. 2008) \\
\hline
\end{tabular}

Table 1. Various mediators capable of inducing tolerogenic characteristics in DCs.

LF15-0195 (LF) is a less toxic structural analog of an immunosuppressive agent 15-deoxyspergualine. Incubation of DC cultures with LF prior to activation leads to general inhibition of the maturation process, characterized by low co-stimulatory molecule and IL-12 expression and the induction of Th2 immune response(Yang, Bernier et al. 2003). The 
blockade of Nf-kB activation by LF proceeds at the level of IKB kinases (IKK), which normally phosphorylate IкBs to induce the release of Nf-кB. LF inhibits IKK in a dosedependent manner, which results in abrogated nuclear translocation of Nf-kB dimmers (Yang, Bernier et al. 2003). We have recently demonstrated that a natural polyphenol resveratrol, present pre-dominantly in red wine and grapes, substantially affects DC differentiation causing development of tolerogenic DCs, resistant to maturation and with the ability to induce IL-10-secreting Tr1-type cells (Svajger, Obermajer et al., 2010). In addition, a relatively unknown non-steroidal anti-inflammatory agent, niflumic acid, was demonstrated to suppress DC maturation with concomitant upregulation of inhibitory molecules (Svajger, Vidmar et al., 2008).

\section{Pre-clinical evaluation of TDCs}

The majority of clinical studies conducted on the use of DCs as therapeutic agents so far have been largely focused on DCs as tumor vaccines. In this context, the first report using a DC vaccine for treatment of patients with B-cell lymphoma was published 15 years ago in Nature Medicine (Hsu, Benike et al. 1996). With increased knowledge in immunosuppressive mechanisms gained throughout recent years, the use of TDCs as negative vaccines for various autoimmune diseases and allogeneic transplantations has also been relatively wellstudied in animal models. For this purpose, TDCs were generated by various means, either using pharmacological manipulation, administration of immunosuppressive cytokines, or even by genetic modification.

\subsection{TDCs in autoimmune disease studies \\ 4.1.1 Type 1 diabetes}

It is now recognized that unresolved inflammation is the loss of balance between 2 biologically opposing arms of acute inflammation termed 'Yin' (pro-inflammatory) and 'Yang' (anti-inflammatory) processes, as a basis for a wide range of chronic inflammatory as well as autoimmune diseases (Khatami 2008). Unresolved inflammation was further suggested to damage tissue integrity in immune-responsive and immune-privilege tissues causing acute and chronic inflammatory diseaases or even cancer (Khatami 2011). Tolerogenic DCs have been shown successful in prevention or amelioration of several autoimmune disease models. The non-obese diabetic (NOD) mouse model is frequently used to explore many aspects of insulin-dependent diabetes mellitus (IDDM) that is caused by the destruction of insulin-producing $\beta$-cells in the pancreas by the immune system (Atkinson and Leiter 1999). It has been shown that the active metabolite of vitamin D can induce TDCs that inhibits NOD mice diabetes development by increasing the function of Tregs (Adorini, Penna et al. 2003). Furthermore, DCs treated ex-vivo with IFN- $\gamma$, a pleiotropic cytokine with both immunostimulatory and immunoregulatory functions, act in an immunosuppressive manner after in vivo transfer (Shinomiya, Fazle Akbar et al. 1999). Such IFN- $\gamma$-treated TDCs were demonstrated to successfully migrate into the pancreas and associated lymphoid tissues, an important feature desired in the generation of both DCs as positive (tumor vaccines) and negative vaccination tools. Transfer of IFN- $\gamma$-treated TDCs prevented the onset of diabetes in 14 out of 19 mice recipients and afforded long-lasting protection against clinical and histological signs of IDDM (Shinomiya, Fazle Akbar et al. 1999). In another approach, bone-marrow derived DCs were differentiated with either granulocyte macrophage colony stimulating factor (GM-CSF) + IL-4 or GM-CSF alone, to 
generate DCs with low MHC class II and co-stimulatory molecule expression. Similarly to results obtained by this study, such DCs also had the capacity to migrate to the pancreas after intravenous injection (Feili-Hariri, Dong et al. 1999) and prevented the onset of IDDM with apparent induction Th1 to Th2 effector response switch.

Additional growth factors were also studied for their capacity to generate TDCs with potential to treat immune-mediated conditions. The granulocyte-colony stimulating factor (G-CSF) was shown to possess immunoregulatory activity in association with the adaptive immune response in previous studies (Hartung, Docke et al. 1995; Mielcarek, Martin et al. 1997; Sloand, Kim et al. 2000). Treatment of NOD mice with G-CSF resulted in protection from development of spontaneous diabetes and triggered the recruitment of immunosuppressive plasmacytoid DCs, that conferred tolerogenic outcome even upon transfer from G-CSF-treated, to vehicle-treated mice (Kared, Masson et al. 2005). Bone marrow-derived DCs from NOD mice have also been used to expand Ag-specific Tregs. As shown by Tarbell et al., DCs generated from NOD mice using GM-CSF and pulsed with single islet auto-antigen expanded $\mathrm{CD} 4{ }^{+} \mathrm{CD} 25^{+} \mathrm{T}$ cells with potent immunosuppressive activity (Tarbell, Yamazaki et al. 2004). This study showed that TDCs can also be used in a manner to generate/expand Ag-specific Tregs to subsequently suppress autoimmune diseases in vivo.

\subsubsection{Rheumatoid arthritis}

Rheumatoid arthritis (RA) is a chronic autoimmune inflammatory disease that mainly affects the synovial tissue of the joints. It has a complex pathogenesis with the involvement of many immune cell types, among which, the DCs seem to play an important role as APCs, as the importance of autoantigen presentation to potentially self-reactive CD4 ${ }^{+} \mathrm{T}$ cells has been emphasized on many occasions (Thomas, MacDonald et al. 1999). Considering the type of DCs, both myeloid, as well as plasmacytoid DCs have been found in blood of patients with RA, in the synovial fluid and in synovial tissue (Lebre and Tak 2009). Current biological treatments of RA include neutralization of cytokine products from APCs, namely TNF-a, IL-1 and IL-6 (Khan, Greenberg et al. 2009). The emerging advanced therapies of RA exploit the tolerogenic capacity of TDCs and research is being focused on ex vivo manipulation of DC function and loading of DCs with respective Ags to later suppress autoimmune responses in vivo.

Using genetically modified DCs expressing immunomodulating proteins, including IL-4, FasL and IDO, all resulted in significant regression of the established disease (Kim, Kim et al. 2001; Morita, Yang et al. 2001; Kim, Kim et al. 2002). In the case of DC-IL-4 and DC-IDOtreated mice, more than half of treated subjects became disease-free for at least two months after treatment and the group using DC-FasL demonstrated a more transient amelioration of the disease (Kim, Kim et al. 2002). Animals that were treated with either DC-IL-4 or DCFasL responded with lowered IFN- $\gamma$ production from spleen-isolated lymphocytes and reduced T-cell proliferation after collagen stimulation. Such studies show the effectiveness of genetically modified DCs in therapeutic prevention of autoimmune diseases.

Dendritic cells modulated with various pharmacological agents have also shown beneficial effects in RA. Treatment of DC progenitors with LF15-0195, an immunosuppressive drug with Nf-kB inhibitory abilities, resulted in generation of TDCs characterized by low expression of MHC class II, CD40 and CD86 co-stimulatory molecules, as well as by poor allostimulatory capacity. Transfer of such TDCs into mice with collagen-induced arthritis 
improved the clinical score of the disease and resulted in reduced $\mathrm{Ab}$ response against collagen (Popov, Li et al. 2006). Histological analysis of inflamed joints in treated mice revealed a decrease of inflammatory cell infiltration. Inhibition of $\mathrm{Nf}-\mathrm{KB}$ is a popular approach towards generating stable, maturation-resistant TDCs and another Nf-kB inhibitor, BAY 11-7082 was also used in context of RA. Treatment of already established bone marrow-derived, Ag-pulsed DCs with BAY 11-7082 and their transfer into C57BL/6 mice with antigen-induced arthritis yielded improved clinical score. This resolvement was dependent on IL-10 (Martin, Capini et al. 2007).

In addition, TDC generation using dexamethasone yielded potent immunosuppressive DCs also effective in prevention of collagen-induced arthritis (van Duivenvoorde, Han et al. 2007). The same study also evaluated the anti-arthritic activity of DCs treated with IL-10 and TNF-a. While all immunomodulatory agents were able to modulate DC function in a way to prevent disease onset, they did so by different mechanisms. Both IL-10- and TNF-a-treated DCs seemed to favor the shift of $\mathrm{T}$ cell effector response from Th1 to Th2, as evident by increased percentage of IL-5- and IL-10-secreting T cells and simultaneous reduction in IgG2a/IgG1 ratio in immunized mice (van Duivenvoorde, Han et al. 2007). On the other hand, dexamethasone treated DCs did not cause an increase in Th2 response and affected the $\mathrm{Ab}$ response in a non-specific manner. Rather, it seems that dexamethasone treated DCs cause an active suppression of Th1 immune responses, which corresponds to their tolerogenic effect.

Interestingly, positive treatment of RA in animal models was also achieved using nonmodified DCs in their immature stage and surprisingly, even DCs treated with maturation stimuli such as TNF-a and TLR ligands. Similar to their ability to induce Tr1 regulatory T cells in vitro as described by Jonuleit (Jonuleit, Schmitt et al. 2000), repetitive injections of iDCs into mice with collagen-induced arhtirits triggered the expansion of regulatory $\mathrm{T}$ cells that protected the mice from the disease (Charbonnier, van Duivenvoorde et al. 2006). Tumor necrosis factor- $\alpha$ has been used in many experimental settings to generate DCs with beneficial effects in animal models of autoimmune disease, including RA disease models (van Duivenvoorde, Louis-Plence et al. 2004; Healy, Collins et al. 2008). Being a pro-inflammatory cytokine it seems paradoxical for TNF-a not to induce full DC activation. However, it has been shown that TNF-a-treated DCs can obtain what is called a semimature phenotype (increased expression of co-stimulatory molecules in the absence of IL12 p70 production) and are able to act in an immunosuppressive manner, inducing the generation of IL-10 secreting Tregs in vivo (Lutz and Schuler 2002; Menges, Rossner et al. 2002). Furthermore, it has been shown that DCs exposed to plasmid DNA or even shortterm to bacterial LPS (not more than 4 hours), yielded DCs with intermediate co-stimulatory molecule expression and low expression of pro-inflammatory cytokines (semi-mature). Such DCs both provided beneficial effects in histological and clinical score of collagen-induced arthritis in mice (Salazar, Aravena et al. 2008; Jaen, Rulle et al. 2009).

\subsubsection{Neuroimmunological disorders}

Multiple sclerosis (MS) is the most common inflammatory disease of the central nervous system (CNS), which is characterized by perivascular inflammatory lesions, demyelination and axonal damage (Steinman 1996). The animal model of MS is represented by experimental autoimmune encephalomyelitis or EAE and serves as a study model induced in susceptible rodent strains by active immunization with myelin Ags. In order for activated, 
myelin-specific encephalitogenic $\mathrm{CD}^{+} \mathrm{T}$ cells to recognize their native protein, they must encounter their cognate APCs in the CNS to be re-activated. It has been shown that Ag presentation is not necessarily limited or due to CNS-resident microglia or astroglial cells, but that a population of DCs present in brain tissue is sufficient to present Ag to T cells and initiate disease development (Greter, Heppner et al. 2005), highlighting the importance of DCs as APCs in MS development.

In an animal model using Lewis rats, iDCs have been used to induce tolerance to myelin basic protein (MBP)-specific immune responses. Immature, bone marrow-derived DCs from Lewis rats, pulsed with MBP in vitro and later injected back into animal subjects, conferred resistance to disease development upon active immunization of animals with MBP and Freund's complete adjuvant (FCA)(Huang, Yang et al. 2000; Xiao, Huang et al. 2001). The therapeutic effect of iDCs was compared with DCs treated with LPS, which did not induce tolerance, suggesting that the activation state of DCs is of crucial importance for their immunosuppressive efficiency. Since the efficiency of DC vaccines for therapy of autoimmune disorders largely relies on the identification of key self-Ags to be used for DC loading, scientists have found a way to avoid this tedious process in some cases. It has been demonstrated that bone-marrow derived DCs from rats already previously inflicted with EAE are seemingly "pulsed" in vivo. Generation of DCs from their bone marrow precursors in vitro can subsequently yield DCs that can later induce tolerance to EAE upon transfer into healthy subjects which are later immunized with MBP and FCA (Xiao, Huang et al. 2001).

The potential of DC manipulation by various immunomodulatory factors has been demonstrated in the context of EAE. In this manner, it has been shown that IFN-Y plays a vital role(Xiao, Wu et al. 2004). Splenic DCs that have been exposed in vitro to IFN-Y exhibit therapeutic potential on acute EAE in Lewis rats as well as on chronic-relapsing EAE in B6 and SJL/L mice. Administered, IFN- $\gamma$-treated DCs triggered Ag-specific production of IFN$\gamma$ and induced apoptosis of CD4 ${ }^{+} \mathrm{T}$ cells associated with increased IDO activity (Xiao, Wu et al. 2004). The reasons for implementing IFN- $\gamma$ in DC activation protocols for therapy of EAE seems logical from multiple viewpoints. Long-recognized as a primary activator of macrophages and primary Th1-driving cytokine, IFN- $\gamma$ is today seen as a pleiotropic cytokine, able to exert effects in both immunogenic and tolerogenic fashion (Zhang 2007). IFN-Y is a strong inducer of some immunosuppressive characteristics in DCs, namely the activity of IDO enzyme which catabolizes tryptophan to cause tryptophan starvation and inhibition of T cell activation. In knockout models, mice deficient for IFN- $\gamma$ had an increased susceptibility to EAE and IFN- $\gamma$ was required for the expression of FoxP3 and the peripheral conversion of CD4+ Tregs in the course of EAE (Wang, Hong et al. 2006; Zhang 2007).

\subsection{TDCs in transplantation}

Although numerous reports demonstrate the effectiveness of immunosuppressive DCs (iDCs, TDCs, semi-mature DCs) in ameliorating or preventing the pathology of a given autoimmune disorder, even more research in recent years has been focused on tolerance induction by DCs in alloimmunity. Indeed, allogeneic transplantation offers some unique opportunities for DC manipulation that are not possible with autoimmune diseases. In a transplantation setting, there is some control over the introduction of donor alloantigens to the recipient, meaning that DCs can be manipulated before or after the initiation of the alloresponse. 
Dendritic cells indeed play a pivotal role in both acute and chronic allograft rejection or acceptance (Morelli and Thomson 2007). After transplantation, the DCs, both that of donor and the recipient, present alloantigens to responding $\mathrm{T}$ cells through either the direct, indirect, or semi-direct mechanism. In direct presentation, the intact donor MHC molecules are presented to the recipient $\mathrm{T}$ cells by donor DCs present in the graft. In the indirect pathway, recipient DCs which have endocytosed and processed alloantigens, present the allopeptides on their own MHC molecules (Gould and Auchincloss 1999). Last through the semi-direct pathway, recipient $\mathrm{T}$ cells recognize intact $\mathrm{MHC}$ molecules that are transferred from donor cells to the surface of recipient DCs (Herrera, Golshayan et al. 2004). The direct pathway is considered to be the most powerful mechanism associated with acute graft rejection, but its influence decreases with time after transplantation. The indirect pathway on the other hand is characteristic of later time-points after transplantation and is considered to play the central role in so-called chronic rejection.

The importance of DCs in allograft acceptance was clearly demonstrated more than 25 years ago, when a report was published demonstrating the prevention of murine islet allograft rejection by Ab-mediated depletion of donor DCs from the islets (Faustman, Steinman et al. 1984). To this day, DCs have been manipulated using a number of pharmacological immunomodulators, immunosuppressive cytokines, as well as by genetic modification, to generate TDCs with the aim to establish long-term graft acceptance.

Genetic modification of DCs to express immunosuppressive factors has been broadly applied in allogeneic transplantation models. Mouse bone marrow-derived DCs transfected with inhibitory molecule FasL displayed a marked increase in the capacity to induce apoptosis of Fas carrying responder cells and inhibited allogeneic T cell proliferation in vitro (Min, Gorczynski et al. 2000). Moreover, transfusion of FasL-expressing DCs into recipient mice prolonged the survival of fully MHC-mismatched cardiac allografts. In addition to inhibitory molecules, a number of studies reported on the successful treatment of allograft rejection using DCs transduced with immunosuppressive cytokines. Transduction of DCs to express IL-10 using adenoviral vectors, led to inhibition of DC mature phenotype and IL-12 secretion. Portal venous infusion of $2 \times 10^{6}$ of IL-10-expressing DCs into animal recipients 7 days before cardiac graft allotransplantation significantly prolonged the survival of allografts. Interestingly, in the same study, IL-10-expressing DCs administered through the tail vein failed to induce graft survival, highlighting the importance of vaccine delivery in transplantation settings (Zhang, Wang et al. 2004). Transforming growth factor- $\beta$ is another molecule exploited for genetic manipulation of TDC generation. However, there seem to be some down-sides in using TGF- $\beta$-expressing DCs in transplantation settings. In one case, DCs transduced to express TGF- $\beta 1$ showed pronounced in vitro immunosuppressive characteristics, but caused only a modest increase in allogeneic heart transplants (Takayama, Kaneko et al. 2002). In another study, TGF- $\beta$-transduced DCs using adenoviral vectors caused prolonged survival of cardiac grafts in $67 \%$ of cases for more than 40 days. However, the administration of TGF- $\beta$-expressing DCs caused fibrosis of the allografts which points to a limitation of using such DC-types in transplantation (Sun, Wang et al. 2002). Attempts have been made also to apply DCs transduced with constructs for both IL-10 and TGF- $\beta$, which led to increased graft survival compared to single cytokine-expressing DCs (Gorczynski, Bransom et al. 2000).

Several experimental data confirmed an essential role of IDO and DCs in immunoregulation of allo-responses (Hainz, Jurgens et al. 2007; Cook, Bickerstaff et al. 2008). In a rat kidney 
transplantation model, allograft tolerance was induced by administration of an anti-CD28 $\mathrm{Ab}$ (Haspot, Seveno et al. 2005). This in vivo tolerance could be broken when the animals were fed with IDO inhibitor 1-MT. Additional evidence was presented in transplantation studies using DCs with forced IDO expression. Pre-treatment of recipient mice with donorspecific bone marrow-derived DCs genetically engineered to express IDO induced skin allograft survival along with reduced expression of crucial inflammatory cytokines by the recipient splenic T cells (Yu, Fang et al. 2008).

It has been shown that graft rejection can be modulated by using non-modified, donor iDCs alone prior to transplantation ( $\mathrm{Fu}, \mathrm{Li}$ et al. 1996; $\mathrm{Lu}$, $\mathrm{Li}$ et al. 1997). In addition, DC differentiation in the presence of GM-CSF and IL-4 at lower concentrations, results in generation of "semi-differentiated" adherent DCs with lower stimulatory capacity than their fully differentiated counterparts (Peche, Trinite et al. 2005). In this manner, such adherent DCs administered just one day prior to transplantation induced significant prolongation of heart allograft survival and suppressed anti-donor humoral and cellular immune responses (Peche, Trinite et al. 2005). In this manner, improper or insufficient DC differentiation clearly contributes to generation of APCs with low stimulatory capacity suitable for cell therapy studies. Similarly, Lutz et al. generated DCs in the presence of low dose GM-CSF, but without additional IL-4. Such DCs were comparable to standard bone marrow-derived DCs in their Ag-presenting capacity, but expressed an immature phenotype and proved maturation-resistant to various stimuli including LPS, CD40 ligand or TNF-a (Lutz, Suri et al. 2000). When transferred to recipient mice 7 days before transplatation, low GM-CSFgenerated DCs induced cardiac allograft survival up to 100 days post-op (Lutz, Suri et al. 2000).

Due to their superior tolerogenic potential, TDCs have been generated by various means with the aim to treat allograft rejection. Since the local tissue environment in a transplantation setting represents a highly inflammatory site, many endogenously released inflammatory factors could have the potential to activate donor or recipient DCs and increasing their immunostimulatory functions. For this purpose, DCs have been made maturation resistant by blockade of $\mathrm{Nf}-\mathrm{kB}$ as the central transcription pathway involved in DC maturation (Yoshimura, Bondeson et al. 2001). Using Nf-kB decoy oligodeoxyribonucleotides (ODNs), the NF- $\mathrm{kB}$ activity and associated expression of costimulatory molecules and cytokines can be suppressed, rendering such DCs tolerogenic and resistant to maturation. Infusion of NF-kB ODN-modified bone marrow-derived DCs into allogeneic recipients prior to cardiac transplantation resulted in significant prolongation of allograft survival without additional immunosuppression by classical immunosuppressive drugs (Giannoukakis, Bonham et al. 2000; Tiao, Lu et al. 2005). Similar results were obtained when Nf-kB ODN-modified DCs were used in a liver transplantation model $(\mathrm{Xu}$, Suo et al. 2004).

Certain pharmacological immunosuppressants have proved valuable tools for TDC generation and have been used in preparation of TDCs as cell therapy tools in transplantation. Rapamycin (or sirolimus) is a widely-known immunosuppressant drug used to treat rejection in organ transplantation, particularly for kidney transplants, and has been in use since 2001 (Hackstein and Thomson 2004). Rapamycin inhibits downstream signaling from the mammalian targets of rapamycin (mTOR) proteins by forming complexes with its intracellular receptor FK506-binding protein 12 (FKBP12)(Sehgal 1998). Rapamycin does not affect the development or differentiation of DCs from their precursors in a 
qualitative manner, like for example corticosteroids, but significantly impairs DC-mediated Ag-uptake and inhibits DC maturation to some extent (Hackstein and Thomson 2004). In terms of indirect pathway of alloantigen recognition as described above, rapamycin-treated, recipient DCs can induce Ag-specific modulation of T cell functions and prolong allograft survival, when pulsed with alloantigen (Taner, Hackstein et al. 2005). Recently, it was demonstrated that rapamycin impairs the maturation of DCs and their ability to stimulate allogeneic T cells, but empowers such DCs to stimulate and expand murine alloantigenspecific $\mathrm{CD}^{+}{ }^{+} \mathrm{CD} 25^{+} \mathrm{FoxP}^{+}$Tregs (Taner, Hackstein et al. 2005). In light of indirect allorecognition, infusion of recipient, rapamycin-treated DCs pulsed with alloantigen prior to transplantation, followed by a low-rapamycin postoperative course, resulted in tolerance establishment to allogeneic graft and indefinite survival of cardiac graft(Turnquist, Raimondi et al. 2007).

\section{Human clinical trials using TDCs}

At the moment, it is a bit difficult to constructively discuss any potential results from human clinical studies using TDCs because until very recently, no results have been published on any aspect of their use in humans. However, at the time of writing this chapter, in June 2011, a group from University of Pittsburgh published their first results from a phase I safety study using TDCs in type 1 diabetic patients (Giannoukakis, Phillips et al. 2011). The intent of the study was to confirm the safety of DC use in autoimmune disease patients, particularly with type I diabetes. The study included a total of 10 patients between 18 and 60 years of age, without otherwise known or suspected health conditions. The patients received autologous DCs either unmanipulated or directed ex vivo towards an immunosuppressive state and $10^{6}$ DCs were administered intradermally in the abdomen every 2 weeks for total of four administrations. Although the study did not demonstrate extensive beneficial effects of DC treatments (based upon measurements of patient glucose and glycated HbA1c levels in blood, as well as C peptide concentrations in serum), the use of autologous DCs proved safe and was well tolerated in adult type 1 diabetic patients (Giannoukakis, Phillips et al. 2011). Indeed, cancer vaccine-associated clinical studies greatly outnumber ones with TDCs and along with numerous existing pre-clinical data, can give a relatively good picture of what can be expected in the near future. In immunology in general, it is extremely difficult to study humans, so any information that can be extrapolated from related studies is of great worth. One thing that has been learned from cancer vaccine trials, and confirmed recently by Giannoukakis et al. (Giannoukakis, Phillips et al. 2011), is that autologous human DC vaccines can be safe and cause minimal side effects. They also confirm that previously observed adverse events such as elevated levels of pro-inflammatory cytokines, fever, chills and general malaise, associated with DC-therapy studies are due to priming of patients with cytokines such as IL-2 and granulocyte-monocyte colony-stimulating factor (Correale, Campoccia et al. 2001; Dhodapkar, Steinman et al. 2001). Another encouragement comes from the successful completion of growing number of phase III trials (source - NIH), crowned by the first approved cellular immunotherapy in April, 2010, by the US Food and Drug Administration (FDA)(Cheever and Higano 2011).

At the time being, almost everything we know about vaccination and therapy using TDCs, comes from rodent models or in vitro-based studies. We are currently at the stage where the tolerogenic mechanisms of TDCs are beginning to be relatively well understood and a 
decent number of protocols for their generation have been developed in the recent years. However, a number of issues related to human studies exist, that have not been sufficiently addressed. The beginning human trials using TDCs thus carry the task of answering many of these questions in the years to come, since direct extrapolation to humans from animal models is impossible. The most important matters that need resolving are:

- What DC type is to be used for particular treatments (iDCs, semi-mature DCs, various TDC types produced by different approaches)

- Generation of standardized protocols for DC generation corresponding to the strict good manufacturing practice (GMP) standards

- What is the proper number of cells to be used in a single application

- What is the ideal route and frequency of DC delivery

- What are the crucial antigens to be presented by DCs

- Will negative vaccination with DCs prove sufficient, or will it come down to combinatorial therapies to achieve long-term success

As of May this year, a second clinical trial using DCs for negative vaccination was registered within the National institutes of Health (NIH) for phase I study, proceeding at the Newcastle University. The study aims to look at the safety, feasibility and acceptability of TDC therapy for patients suffering from RA. The therapeutic will represent autologous TDCs, derived from the patients peripheral blood leukocytes by leukapheresis and ex vivo culture and intends to include 12 patients in total. Patients will be chosen for their RA pathology and at least one swollen knee joint. The DCs will be administered directly into the knee joint and observed by arthroscopy for disease assessment (source - NIH).

\section{Concluding remarks}

Undeniable progress has been made in the field of therapeutic tolerance induction using immunosuppressive DCs, and there is an evolving pool of knowledge that we hope will perpetuate clinical research in the future. We now know much about how DCs exercise their tolerogenic function, both to auto- or allo-antigens, and of the way how to modulate DC function in the laboratory. However, some crucial matters need to be resolved on how will these cells behave once applied into the human body. In addition, the challenge awaits on how can we fine-tune the process ranging from TDC generation to their application and observing the clinical score, while at the same time meeting the quality standards required without risking excessive funds.

\section{References}

Adorini, L., G. Penna, et al. (2003). "Tolerogenic dendritic cells induced by vitamin D receptor ligands enhance regulatory $\mathrm{T}$ cells inhibiting allograft rejection and autoimmune diseases." J Cell Biochem 88(2): 227-233.

Allavena, P., L. Piemonti, et al. (1998). "IL-10 prevents the differentiation of monocytes to dendritic cells but promotes their maturation to macrophages." Eur J Immunol 28(1): 359-369.

Andersson, J., D. Q. Tran, et al. (2008). "CD4+ FoxP3+ regulatory T cells confer infectious tolerance in a TGF-beta-dependent manner." J Exp Med 205(9): 1975-1981. 
Atkinson, M. A. and E. H. Leiter (1999). "The NOD mouse model of type 1 diabetes: as good as it gets?" Nat Med 5(6): 601-604.

Auphan, N., J. A. DiDonato, et al. (1995). "Immunosuppression by glucocorticoids: inhibition of NF-kappa B activity through induction of I kappa B synthesis." Science 270(5234): 286-290.

Banchereau, J. and R. M. Steinman (1998). "Dendritic cells and the control of immunity." Nature 392(6673): 245-252.

Belkaid, Y. and G. Oldenhove (2008). "Tuning microenvironments: induction of regulatory T cells by dendritic cells." Immunity 29(3): 362-371.

Berer, A., J. Stockl, et al. (2000). "1,25-Dihydroxyvitamin D(3) inhibits dendritic cell differentiation and maturation in vitro." Exp Hematol 28(5): 575-583.

Blazquez, A. B. and M. C. Berin (2008). "Gastrointestinal dendritic cells promote Th2 skewing via OX40L." J Immunol 180(7): 4441-4450.

Brown, J. A., D. M. Dorfman, et al. (2003). "Blockade of programmed death-1 ligands on dendritic cells enhances $\mathrm{T}$ cell activation and cytokine production." J Immunol 170(3): 1257-1266.

Carbonneil, C., H. Saidi, et al. (2004). "Dendritic cells generated in the presence of interferonalpha stimulate allogeneic CD4+ T-cell proliferation: modulation by autocrine IL10, enhanced T-cell apoptosis and T regulatory type 1 cells." Int Immunol 16(7): 1037-1052.

Cella, M., F. Sallusto, et al. (1997). "Origin, maturation and antigen presenting function of dendritic cells." Curr Opin Immunol 9(1): 10-16.

Chang, C. C., R. Ciubotariu, et al. (2002). "Tolerization of dendritic cells by T(S) cells: the crucial role of inhibitory receptors ILT3 and ILT4." Nat Immunol 3(3): 237-243.

Charbonnier, L. M., L. M. van Duivenvoorde, et al. (2006). "Immature dendritic cells suppress collagen-induced arthritis by in vivo expansion of $\mathrm{CD} 49 \mathrm{~b}+$ regulatory $\mathrm{T}$ cells." J Immunol 177(6): 3806-3813.

Cheever, M. A. and C. S. Higano (2011). "PROVENGE (Sipuleucel-T) in Prostate Cancer: The First FDA-Approved Therapeutic Cancer Vaccine." Clin Cancer Res 17(11): 35203526.

Chorny, A., E. Gonzalez-Rey, et al. (2005). "Vasoactive intestinal peptide induces regulatory dendritic cells with therapeutic effects on autoimmune disorders." Proc Natl Acad Sci U S A 102(38): 13562-13567.

Cohen, N., E. Mouly, et al. (2006). "GILZ expression in human dendritic cells redirects their maturation and prevents antigen-specific T lymphocyte response." Blood 107(5): 2037-2044.

Cook, C. H., A. A. Bickerstaff, et al. (2008). "Spontaneous renal allograft acceptance associated with "regulatory" dendritic cells and IDO." J Immunol 180(5): 3103-3112.

Coombes, J. L., K. R. Siddiqui, et al. (2007). "A functionally specialized population of mucosal CD103+ DCs induces Foxp3+ regulatory T cells via a TGF-beta and retinoic acid-dependent mechanism." J Exp Med 204(8): 1757-1764.

Correale, P., G. Campoccia, et al. (2001). "Recruitment of dendritic cells and enhanced antigen-specific immune reactivity in cancer patients treated with hr-GM-CSF (Molgramostim) and hr-IL-2. results from a phase Ib clinical trial." Eur J Cancer 37(7): 892-902. 
De Bosscher, K., W. Vanden Berghe, et al. (2000). "Glucocorticoids repress NF-kappaBdriven genes by disturbing the interaction of p65 with the basal transcription machinery, irrespective of coactivator levels in the cell." Proc Natl Acad Sci U S A 97(8): 3919-3924.

De Smedt, T., M. Van Mechelen, et al. (1997). "Effect of interleukin-10 on dendritic cell maturation and function." Eur J Immunol 27(5): 1229-1235.

Della Bella, S., S. Nicola, et al. (2004). "Are interleukin-16 and thrombopoietin new tools for the in vitro generation of dendritic cells?" Blood 104(13): 4020-4028.

Dhodapkar, M. V., R. M. Steinman, et al. (2001). "Antigen-specific inhibition of effector T cell function in humans after injection of immature dendritic cells." J Exp Med 193(2): 233-238.

Dong, X., W. Lutz, et al. (2005). "Regulation of relB in dendritic cells by means of modulated association of vitamin D receptor and histone deacetylase 3 with the promoter." Proc Natl Acad Sci U S A 102(44): 16007-16012.

Fallarino, F., U. Grohmann, et al. (2003). "Modulation of tryptophan catabolism by regulatory T cells." Nat Immunol 4(12): 1206-1212.

Faunce, D. E., A. Terajewicz, et al. (2004). "Cutting edge: in vitro-generated tolerogenic APC induce $\mathrm{CD} 8+\mathrm{T}$ regulatory cells that can suppress ongoing experimental autoimmune encephalomyelitis." J Immunol 172(4): 1991-1995.

Faustman, D. L., R. M. Steinman, et al. (1984). "Prevention of rejection of murine islet allografts by pretreatment with anti-dendritic cell antibody." Proc Natl Acad Sci U S A 81(12): 3864-3868.

Feili-Hariri, M., X. Dong, et al. (1999). "Immunotherapy of NOD mice with bone marrowderived dendritic cells." Diabetes 48(12): 2300-2308.

Fiorentino, D. F., A. Zlotnik, et al. (1991). "IL-10 acts on the antigen-presenting cell to inhibit cytokine production by Th1 cells." J Immunol 146(10): 3444-3451.

Freeman, G. J., A. J. Long, et al. (2000). "Engagement of the PD-1 immunoinhibitory receptor by a novel B7 family member leads to negative regulation of lymphocyte activation." J Exp Med 192(7): 1027-1034.

Fu, F., Y. Li, et al. (1996). "Costimulatory molecule-deficient dendritic cell progenitors (MHC class II+, CD80dim, CD86-) prolong cardiac allograft survival in nonimmunosuppressed recipients." Transplantation 62(5): 659-665.

Geissmann, F., P. Revy, et al. (1999). "TGF-beta 1 prevents the noncognate maturation of human dendritic Langerhans cells." J Immunol 162(8): 4567-4575.

Ghiringhelli, F., P. E. Puig, et al. (2005). "Tumor cells convert immature myeloid dendritic cells into TGF-beta-secreting cells inducing CD4+CD25+ regulatory $\mathrm{T}$ cell proliferation." J Exp Med 202(7): 919-929.

Giannoukakis, N., C. A. Bonham, et al. (2000). "Prolongation of cardiac allograft survival using dendritic cells treated with NF-kB decoy oligodeoxyribonucleotides." Mol Ther 1(5 Pt 1): 430-437.

Giannoukakis, N., B. Phillips, et al. (2011). "Phase I (Safety) Study of Autologous Tolerogenic Dendritic Cells in Type 1 Diabetic Patients." Diabetes Care.

Gorczynski, R. M., J. Bransom, et al. (2000). "Synergy in induction of increased renal allograft survival after portal vein infusion of dendritic cells transduced to express TGFbeta and IL-10, along with administration of $\mathrm{CHO}$ cells expressing the regulatory molecule OX-2." Clin Immunol 95(3): 182-189. 
Gould, D. S. and H. Auchincloss, Jr. (1999). "Direct and indirect recognition: the role of MHC antigens in graft rejection." Immunol Today 20(2): 77-82.

Gregori, S., D. Tomasoni, et al. (2010). "Differentiation of type $1 \mathrm{~T}$ regulatory cells (Tr1) by tolerogenic DC-10 requires the IL-10-dependent ILT4/HLA-G pathway." Blood 116(6): 935-944.

Greter, M., F. L. Heppner, et al. (2005). "Dendritic cells permit immune invasion of the CNS in an animal model of multiple sclerosis." Nat Med 11(3): 328-334.

Grohmann, U., R. Bianchi, et al. (2000). "IFN-gamma inhibits presentation of a tumor/self peptide by CD8 alpha- dendritic cells via potentiation of the CD8 alpha+ subset." $J$ Immunol 165(3): 1357-1363.

Grohmann, U., F. Fallarino, et al. (2003). "A defect in tryptophan catabolism impairs tolerance in nonobese diabetic mice." J Exp Med 198(1): 153-160.

Grohmann, U., F. Fallarino, et al. (2003). "Tolerance, DCs and tryptophan: much ado about IDO." Trends Immunol 24(5): 242-248.

Grohmann, U., C. Orabona, et al. (2002). "CTLA-4-Ig regulates tryptophan catabolism in vivo." Nat Immunol 3(11): 1097-1101.

Groux, H., A. O'Garra, et al. (1997). "A CD4+ T-cell subset inhibits antigen-specific T-cell responses and prevents colitis." Nature 389(6652): 737-742.

Hackstein, H. and A. W. Thomson (2004). "Dendritic cells: emerging pharmacological targets of immunosuppressive drugs." Nat Rev Immunol 4(1): 24-34.

Hainz, U., B. Jurgens, et al. (2007). "The role of indoleamine 2,3-dioxygenase in transplantation." Transpl Int 20(2): 118-127.

Hartung, T., W. D. Docke, et al. (1995). "Effect of granulocyte colony-stimulating factor treatment on ex vivo blood cytokine response in human volunteers." Blood 85(9): 2482-2489.

Haspot, F., C. Seveno, et al. (2005). "Anti-CD28 antibody-induced kidney allograft tolerance related to tryptophan degradation and TCR class II B7 regulatory cells." Am J Transplant 5(10): 2339-2348.

Hayashi, T., J. H. Mo, et al. (2007). "3-Hydroxyanthranilic acid inhibits PDK1 activation and suppresses experimental asthma by inducing T cell apoptosis." Proc Natl Acad Sci $U$ $S$ A 104(47): 18619-18624.

Healy, L. J., H. L. Collins, et al. (2008). "Systemic administration of tolerogenic dendritic cells ameliorates murine inflammatory arthritis." Open Rheumatol J 2: 71-80.

Herrera, O. B., D. Golshayan, et al. (2004). "A novel pathway of alloantigen presentation by dendritic cells." J Immunol 173(8): 4828-4837.

Hou, D. Y., A. J. Muller, et al. (2007). "Inhibition of indoleamine 2,3-dioxygenase in dendritic cells by stereoisomers of 1-methyl-tryptophan correlates with antitumor responses." Cancer Res 67(2): 792-801.

Hsu, F. J., C. Benike, et al. (1996). "Vaccination of patients with B-cell lymphoma using autologous antigen-pulsed dendritic cells." Nat Med 2(1): 52-58.

Huang, Y. M., J. S. Yang, et al. (2000). "Autoantigen-pulsed dendritic cells induce tolerance to experimental allergic encephalomyelitis (EAE) in Lewis rats." Clin Exp Immunol 122(3): 437-444.

Inaba, K., S. Turley, et al. (2000). "The formation of immunogenic major histocompatibility complex class II-peptide ligands in lysosomal compartments of dendritic cells is regulated by inflammatory stimuli." J Exp Med 191(6): 927-936. 
Jaen, O., S. Rulle, et al. (2009). "Dendritic cells modulated by innate immunity improve collagen-induced arthritis and induce regulatory $\mathrm{T}$ cells in vivo." Immunology 126(1): 35-44.

Jonuleit, H., E. Schmitt, et al. (2000). "Induction of interleukin 10-producing, nonproliferating CD4(+) T cells with regulatory properties by repetitive stimulation with allogeneic immature human dendritic cells." J Exp Med 192(9): 1213-1222.

Kadowaki, N. (2007). "Dendritic cells: a conductor of T cell differentiation." Allergol Int 56(3): 193-199.

Kared, H., A. Masson, et al. (2005). "Treatment with granulocyte colony-stimulating factor prevents diabetes in NOD mice by recruiting plasmacytoid dendritic cells and functional CD4(+)CD25(+) regulatory T-cells." Diabetes 54(1): 78-84.

Khan, S., J. D. Greenberg, et al. (2009). "Dendritic cells as targets for therapy in rheumatoid arthritis." Nat Rev Rheumatol 5(10): 566-571.

Khatami, M. (2008). "'Yin and Yang' in inflammation: duality in innate immune cell function and tumorigenesis." Expert Opin Biol Ther 8(10): 1461-1472.

Khatami, M. (2011). "Unresolved inflammation: 'immune tsunami' or erosion of integrity in immune-privileged and immune-responsive tissues and acute and chronic inflammatory diseases or cancer." Expert Opin Biol Ther.

Kim, S. H., S. Kim, et al. (2001). "Effective treatment of established murine collagen-induced arthritis by systemic administration of dendritic cells genetically modified to express IL-4." J Immunol 166(5): 3499-3505.

Kim, S. H., S. Kim, et al. (2002). "Effective treatment of established mouse collagen-induced arthritis by systemic administration of dendritic cells genetically modified to express FasL." Mol Ther 6(5): 584-590.

Lanzavecchia, A. and F. Sallusto (2001). "Regulation of T cell immunity by dendritic cells." Cell 106(3): 263-266.

Latchman, Y., C. R. Wood, et al. (2001). "PD-L2 is a second ligand for PD-1 and inhibits T cell activation." Nat Immunol 2(3): 261-268.

Lebre, M. C. and P. P. Tak (2009). "Dendritic cells in rheumatoid arthritis: Which subset should be used as a tool to induce tolerance?" Hum Immunol 70(5): 321-324.

Legge, K. L. and T. J. Braciale (2005). "Lymph node dendritic cells control CD8+ T cell responses through regulated FasL expression." Immunity 23(6): 649-659.

Levings, M. K., S. Gregori, et al. (2005). "Differentiation of Tr1 cells by immature dendritic cells requires IL-10 but not CD25+CD4+ Tr cells." Blood 105(3): 1162-1169.

$\mathrm{Lu}, \mathrm{L} ., \mathrm{W}$. Li, et al. (1997). "Blockade of the CD40-CD40 ligand pathway potentiates the capacity of donor-derived dendritic cell progenitors to induce long-term cardiac allograft survival." Transplantation 64(12): 1808-1815.

Luo, X., K. V. Tarbell, et al. (2007). "Dendritic cells with TGF-beta1 differentiate naive CD4+CD25- T cells into islet-protective Foxp3+ regulatory T cells." Proc Natl Acad Sci U S A 104(8): 2821-2826.

Lutz, M. B. and G. Schuler (2002). "Immature, semi-mature and fully mature dendritic cells: which signals induce tolerance or immunity?" Trends Immunol 23(9): 445-449.

Lutz, M. B., R. M. Suri, et al. (2000). "Immature dendritic cells generated with low doses of GM-CSF in the absence of IL-4 are maturation resistant and prolong allograft survival in vivo." Eur J Immunol 30(7): 1813-1822. 
MacDonald, A. S. and R. M. Maizels (2008). "Alarming dendritic cells for Th2 induction." J Exp Med 205(1): 13-17.

Manavalan, J. S., P. C. Rossi, et al. (2003). "High expression of ILT3 and ILT4 is a general feature of tolerogenic dendritic cells." Transpl Immunol 11(3-4): 245-258.

Martin, E., C. Capini, et al. (2007). "Antigen-specific suppression of established arthritis in mice by dendritic cells deficient in NF-kappaB." Arthritis Rheum 56(7): 2255-2266.

Meier, A., A. Bagchi, et al. (2008). "Upregulation of PD-L1 on monocytes and dendritic cells by HIV-1 derived TLR ligands." AIDS 22(5): 655-658.

Mellman, I. and R. M. Steinman (2001). "Dendritic cells: specialized and regulated antigen processing machines." Cell 106(3): 255-258.

Mellor, A. L. and D. H. Munn (2004). "IDO expression by dendritic cells: tolerance and tryptophan catabolism." Nat Rev Immunol 4(10): 762-774.

Menges, M., S. Rossner, et al. (2002). "Repetitive injections of dendritic cells matured with tumor necrosis factor alpha induce antigen-specific protection of mice from autoimmunity." J Exp Med 195(1): 15-21.

Mennechet, F. J. and G. Uze (2006). "Interferon-lambda-treated dendritic cells specifically induce proliferation of FOXP3-expressing suppressor T cells." Blood 107(11): 44174423 .

Mielcarek, M., P. J. Martin, et al. (1997). "Suppression of alloantigen-induced T-cell proliferation by CD14+ cells derived from granulocyte colony-stimulating factormobilized peripheral blood mononuclear cells." Blood 89(5): 1629-1634.

Min, W. P., R. Gorczynski, et al. (2000). "Dendritic cells genetically engineered to express Fas ligand induce donor-specific hyporesponsiveness and prolong allograft survival." $J$ Immunol 164(1): 161-167.

Moore, K. W., R. de Waal Malefyt, et al. (2001). "Interleukin-10 and the interleukin-10 receptor." Annu Rev Immunol 19: 683-765.

Moore, K. W., P. Vieira, et al. (1990). "Homology of cytokine synthesis inhibitory factor (IL10 ) to the Epstein-Barr virus gene BCRFI." Science 248(4960): 1230-1234.

Morelli, A. E. and A. W. Thomson (2007). "Tolerogenic dendritic cells and the quest for transplant tolerance." Nat Rev Immunol 7(8): 610-621.

Morita, Y., J. Yang, et al. (2001). "Dendritic cells genetically engineered to express IL-4 inhibit murine collagen-induced arthritis." J Clin Invest 107(10): 1275-1284.

Moser, M. (2003). "Dendritic cells in immunity and tolerance-do they display opposite functions?" Immunity 19(1): 5-8.

Munn, D. H., M. Zhou, et al. (1998). "Prevention of allogeneic fetal rejection by tryptophan catabolism." Science 281(5380): 1191-1193.

Nagata, S. and P. Golstein (1995). "The Fas death factor." Science 267(5203): 1449-1456.

Ohnmacht, C., A. Pullner, et al. (2009). "Constitutive ablation of dendritic cells breaks selftolerance of CD4 T cells and results in spontaneous fatal autoimmunity." J Exp Med 206(3): 549-559.

Orabona, C. and U. Grohmann (2011). "Indoleamine 2,3-dioxygenase and regulatory function: tryptophan starvation and beyond." Methods Mol Biol 677: 269-280.

Peche, H., B. Trinite, et al. (2005). "Prolongation of heart allograft survival by immature dendritic cells generated from recipient type bone marrow progenitors." Am J Transplant 5(2): 255-267. 
Penna, G. and L. Adorini (2000). "1 Alpha,25-dihydroxyvitamin D3 inhibits differentiation, maturation, activation, and survival of dendritic cells leading to impaired alloreactive T cell activation." J Immunol 164(5): 2405-2411.

Penna, G., A. Roncari, et al. (2005). "Expression of the inhibitory receptor ILT3 on dendritic cells is dispensable for induction of CD4+Foxp3+ regulatory $\mathrm{T}$ cells by 1,25dihydroxyvitamin D3." Blood 106(10): 3490-3497.

Piemonti, L., P. Monti, et al. (1999). "Glucocorticoids affect human dendritic cell differentiation and maturation." J Immunol 162(11): 6473-6481.

Piemonti, L., P. Monti, et al. (2000). "Vitamin D3 affects differentiation, maturation, and function of human monocyte-derived dendritic cells." J Immunol 164(9): 4443-4451.

Platten, M., P. P. Ho, et al. (2005). "Treatment of autoimmune neuroinflammation with a synthetic tryptophan metabolite." Science 310(5749): 850-855.

Popov, I., M. Li, et al. (2006). "Preventing autoimmune arthritis using antigen-specific immature dendritic cells: a novel tolerogenic vaccine." Arthritis Res Ther 8(5): R141.

Pulendran, B., K. Palucka, et al. (2001). "Sensing pathogens and tuning immune responses." Science 293(5528): 253-256.

Romani, L., F. Fallarino, et al. (2008). "Defective tryptophan catabolism underlies inflammation in mouse chronic granulomatous disease." Nature 451(7175): 211-215.

Roncarolo, M. G., S. Gregori, et al. (2006). "Interleukin-10-secreting type 1 regulatory T cells in rodents and humans." Immunol Rev 212: 28-50.

Rutella, S., S. Danese, et al. (2006). "Tolerogenic dendritic cells: cytokine modulation comes of age." Blood 108(5): 1435-1440.

Sakaguchi, S., T. Yamaguchi, et al. (2008). "Regulatory T cells and immune tolerance." Cell 133(5): 775-787.

Salazar, L., O. Aravena, et al. (2008). "Modulation of established murine collagen-induced arthritis by a single inoculation of short-term lipopolysaccharide-stimulated dendritic cells." Ann Rheum Dis 67(9): 1235-1241.

Scheinman, R. I., P. C. Cogswell, et al. (1995). "Role of transcriptional activation of I kappa B alpha in mediation of immunosuppression by glucocorticoids." Science 270(5234): 283-286.

Scheinman, R. I., A. Gualberto, et al. (1995). "Characterization of mechanisms involved in transrepression of NF-kappa B by activated glucocorticoid receptors." Mol Cell Biol 15(2): 943-953.

Schreiner, B., M. Mitsdoerffer, et al. (2004). "Interferon-beta enhances monocyte and dendritic cell expression of B7-H1 (PD-L1), a strong inhibitor of autologous T-cell activation: relevance for the immune modulatory effect in multiple sclerosis." $J$ Neuroimmunol 155(1-2): 172-182.

Sehgal, S. N. (1998). "Rapamune (RAPA, rapamycin, sirolimus): mechanism of action immunosuppressive effect results from blockade of signal transduction and inhibition of cell cycle progression." Clin Biochem 31(5): 335-340.

Shinomiya, M., S. M. Fazle Akbar, et al. (1999). "Transfer of dendritic cells (DC) ex vivo stimulated with interferon-gamma (IFN-gamma) down-modulates autoimmune diabetes in non-obese diabetic (NOD) mice." Clin Exp Immunol 117(1): 38-43.

Sloand, E. M., S. Kim, et al. (2000). "Pharmacologic doses of granulocyte colony-stimulating factor affect cytokine production by lymphocytes in vitro and in vivo." Blood 95(7): 2269-2274. 
Steinbrink, K., E. Graulich, et al. (2002). "CD4(+) and CD8(+) anergic T cells induced by interleukin-10-treated human dendritic cells display antigen-specific suppressor activity." Blood 99(7): 2468-2476.

Steinbrink, K., M. Wolfl, et al. (1997). "Induction of tolerance by IL-10-treated dendritic cells." J Immunol 159(10): 4772-4780.

Steinman, L. (1996). "Multiple sclerosis: a coordinated immunological attack against myelin in the central nervous system." Cell 85(3): 299-302.

Steinman, M., J. G. Topliss, et al. (1973). "1-Polyfluoroalkylbenzodiazepines; 1." J Med Chem 16(12): 1354-1360.

Steinman, R. M., D. Hawiger, et al. (2003). "Tolerogenic dendritic cells." Annu Rev Immunol 21: 685-711.

Steinman, R. M., S. Turley, et al. (2000). "The induction of tolerance by dendritic cells that have captured apoptotic cells." J Exp Med 191(3): 411-416.

Sun, W., Q. Wang, et al. (2002). "TGF-beta(1) gene modified immature dendritic cells exhibit enhanced tolerogenicity but induce allograft fibrosis in vivo." J Mol Med 80(8): 514523.

Svajger, U., N. Obermajer, et al. (2010). "Dendritic cells treated with resveratrol during differentiation from monocytes gain substantial tolerogenic properties upon activation." Immunology 129(4): 525-535

Svajger, U., N. Obermajer, et al. (2010). "Novel findings in drug-induced dendritic cell tolerogenicity." Int Rev Immunol 29(6): 574-607.

Svajger, U., A. Vidmar, et al. (2008). "Niflumic acid renders dendritic cells tolerogenic and upregulates inhibitory molecules ILT3 and ILT4." Int Immunopharmacol 8(7): 997-1005.

Szeto, F. L., J. Sun, et al. (2007). "Involvement of the vitamin D receptor in the regulation of NF-kappaB activity in fibroblasts." J Steroid Biochem Mol Biol 103(3-5): 563-566.

Takayama, T., K. Kaneko, et al. (2002). "Retroviral delivery of transforming growth factorbeta1 to myeloid dendritic cells: inhibition of T-cell priming ability and influence on allograft survival." Transplantation 74(1): 112-119.

Takayama, T., Y. Nishioka, et al. (1998). "Retroviral delivery of viral interleukin-10 into myeloid dendritic cells markedly inhibits their allostimulatory activity and promotes the induction of T-cell hyporesponsiveness." Transplantation 66(12): 1567-1574.

Takeuchi, M., P. Alard, et al. (1998). "TGF-beta promotes immune deviation by altering accessory signals of antigen-presenting cells." J Immunol 160(4): 1589-1597.

Taner, T., H. Hackstein, et al. (2005). "Rapamycin-treated, alloantigen-pulsed host dendritic cells induce ag-specific T cell regulation and prolong graft survival." Am J Transplant 5(2): 228-236.

Tarbell, K. V., S. Yamazaki, et al. (2004). "CD25+ CD4+ T cells, expanded with dendritic cells presenting a single autoantigenic peptide, suppress autoimmune diabetes." J Exp Med 199(11): 1467-1477.

Thomas, R., K. P. MacDonald, et al. (1999). "Dendritic cells and the pathogenesis of rheumatoid arthritis." J Leukoc Biol 66(2): 286-292.

Tiao, M. M., L. Lu, et al. (2005). "Prolongation of cardiac allograft survival by systemic administration of immature recipient dendritic cells deficient in NF-kappaB activity." Ann Surg 241(3): 497-505.

Turnquist, H. R., G. Raimondi, et al. (2007). "Rapamycin-conditioned dendritic cells are poor stimulators of allogeneic CD4+ $\mathrm{T}$ cells, but enrich for antigen-specific Foxp3+ $\mathrm{T}$ regulatory cells and promote organ transplant tolerance." J Immunol 178(11): 7018-7031. 
van Beelen, A. J., Z. Zelinkova, et al. (2007). "Stimulation of the intracellular bacterial sensor NOD2 programs dendritic cells to promote interleukin-17 production in human memory T cells." Immunity 27(4): 660-669.

van Duivenvoorde, L. M., W. G. Han, et al. (2007). "Immunomodulatory dendritic cells inhibit Th1 responses and arthritis via different mechanisms." J Immunol 179(3): 1506-1515.

van Duivenvoorde, L. M., P. Louis-Plence, et al. (2004). "Antigen-specific immunomodulation of collagen-induced arthritis with tumor necrosis factorstimulated dendritic cells." Arthritis Rheum 50(10): 3354-3364.

Verginis, P., H. S. Li, et al. (2005). "Tolerogenic semimature dendritic cells suppress experimental autoimmune thyroiditis by activation of thyroglobulin-specific CD4+CD25+ T cells." J Immunol 174(11): 7433-7439.

Vieira, P. L., E. C. de Jong, et al. (2000). "Development of Th1-inducing capacity in myeloid dendritic cells requires environmental instruction." J Immunol 164(9): 4507-4512.

Vlad, G., F. Piazza, et al. (2003). "Interleukin-10 induces the upregulation of the inhibitory receptor ILT4 in monocytes from HIV positive individuals." Hum Immunol 64(5): 483-489.

Wang, Z., J. Hong, et al. (2006). "Role of IFN-gamma in induction of Foxp3 and conversion of CD4+ CD25- T cells to CD4+ Tregs." J Clin Invest 116(9): 2434-2441.

Weiner, H. L. (2001). "The mucosal milieu creates tolerogenic dendritic cells and T(R)1 and $\mathrm{T}(\mathrm{H}) 3$ regulatory cells." Nat Immunol 2(8): 671-672.

Willems, F., A. Marchant, et al. (1994). "Interleukin-10 inhibits B7 and intercellular adhesion molecule-1 expression on human monocytes." Eur J Immunol 24(4): 1007-1009.

Xia, C. Q., R. Peng, et al. (2005). "Dexamethasone induces IL-10-producing monocytederived dendritic cells with durable immaturity." Scand J Immunol 62(1): 45-54.

Xiao, B. G., Y. M. Huang, et al. (2001). "Bone marrow-derived dendritic cells from experimental allergic encephalomyelitis induce immune tolerance to EAE in Lewis rats." Clin Exp Immunol 125(2): 300-309.

Xiao, B. G., X. C. Wu, et al. (2004). "Therapeutic potential of IFN-gamma-modified dendritic cells in acute and chronic experimental allergic encephalomyelitis." Int Immunol 16(1): 13-22.

Xu, M. Q., Y. P. Suo, et al. (2004). "Prolongation of liver allograft survival by dendritic cells modified with NF-kappaB decoy oligodeoxynucleotides." World J Gastroenterol 10(16): 2361-2368.

Yamazaki, S., D. Dudziak, et al. (2008). "CD8+ CD205+ splenic dendritic cells are specialized to induce Foxp3+ regulatory T cells." J Immunol 181(10): 6923-6933.

Yang, J., S. M. Bernier, et al. (2003). "LF15-0195 generates tolerogenic dendritic cells by suppression of NF-kappaB signaling through inhibition of IKK activity." J Leukoc Biol 74(3): 438-447.

Yoshimura, S., J. Bondeson, et al. (2001). "Effective antigen presentation by dendritic cells is NF-kappaB dependent: coordinate regulation of MHC, co-stimulatory molecules and cytokines." Int Immunol 13(5): 675-683.

Yu, G., M. Fang, et al. (2008). "Steady state dendritic cells with forced IDO expression induce skin allograft tolerance by upregulation of regulatory T cells." Transpl Immunol 18(3): 208-219.

Zhang, J. (2007). "Yin and yang interplay of IFN-gamma in inflammation and autoimmune disease." J Clin Invest 117(4): 871-873. 
Zhang, M., Q. Wang, et al. (2004). "Effective induction of immune tolerance by portal venous infusion with IL-10 gene-modified immature dendritic cells leading to prolongation of allograft survival." J Mol Med 82(4): 240-249. 


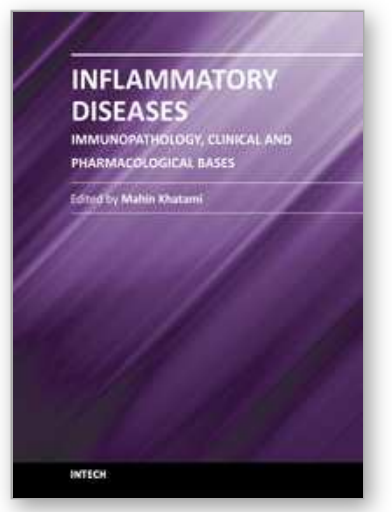

\author{
Inflammatory Diseases - Immunopathology, Clinical and \\ Pharmacological Bases \\ Edited by Dr Mahin Khatami
}

ISBN 978-953-307-911-0

Hard cover, 396 pages

Publisher InTech

Published online 10, February, 2012

Published in print edition February, 2012

This book is a collection of comprehensive reviews contributed by experts in the diverse fields of acute and chronic inflammatory diseases, with emphasis on current pharmacological and diagnostic options. Interested professionals are also encouraged to review the contributions made by experts in a second related book entitled "Inflammation, Chronic Diseases and Cancer"; it deals with immunobiology, clinical reviews, and perspectives of the mechanisms of immune inflammatory responses that are involved in alterations of immune dynamics during the genesis, progression and manifestation of a number of inflammatory diseases and cancers, as well as perspectives for diagnosis, and treatment or prevention of these disabling and potentially preventable diseases, particularly for the growing population of older adults around the globe.

\title{
How to reference
}

In order to correctly reference this scholarly work, feel free to copy and paste the following:

Urban Švajger and Borut Štrukelj (2012). Tolerogenic Dendritic Cells for Therapy of Immune-Mediated Inflammatory Diseases, Inflammatory Diseases - Immunopathology, Clinical and Pharmacological Bases, Dr Mahin Khatami (Ed.), ISBN: 978-953-307-911-0, InTech, Available from:

http://www.intechopen.com/books/inflammatory-diseases-immunopathology-clinical-and-pharmacologicalbases/tolerogenic-dendritic-cells-for-therapy-of-immune-mediated-diseases

\section{INTECH}

open science | open minds

\author{
InTech Europe \\ University Campus STeP Ri \\ Slavka Krautzeka 83/A \\ 51000 Rijeka, Croatia \\ Phone: +385 (51) 770447 \\ Fax: +385 (51) 686166 \\ www.intechopen.com
}

\author{
InTech China \\ Unit 405, Office Block, Hotel Equatorial Shanghai \\ No.65, Yan An Road (West), Shanghai, 200040, China \\ 中国上海市延安西路65号上海国际贵都大饭店办公楼 405 单元 \\ Phone: +86-21-62489820 \\ Fax: +86-21-62489821
}


(C) 2012 The Author(s). Licensee IntechOpen. This is an open access article distributed under the terms of the Creative Commons Attribution 3.0 License, which permits unrestricted use, distribution, and reproduction in any medium, provided the original work is properly cited. 